\title{
HEALTHY LIFESTYLE - A SURVEY AMONG YOUNG BULGARIANS
}

\author{
Evelina Miloshova \\ NSA “V. Levski”, Sofia, Bulgaria
}

Key words: youth, healthy lifestyle, GSHS, chronic non-communicable diseases

Introduction: Extending life expectancy and improving its quality is of particular importance to the individual as well as to the society as a whole. The main cause of poor health is the development of one or more diseases that occur in different periods of a person's life. These diseases are provoked by the effects of a number of factors, some related to the individual's behavior and attitude to his own health.

Developing basic health habits occur at childhood and youth, but some harmful and dangerous to health behavior is also developed at the same age, behavior that leads to future chronic diseases.

Nutritional habits that affect health can be divided into positive (fruit and vegetable intake) and negative (nonalcoholic, carbonated beverages and fast foods intake).

The fruits and vegetables are rich in vitamins, minerals, and vegetable fiber. Fruit and vegetable intake leads to good health, and it is an important attribute of a healthy diet. According to some studies only $30 \%$ of children consumed fresh fruits three to five times a week. On the other hand, high intake of sugar and sugar-containing products and beverages is common to the young Bulgarians, but affects negatively on health and leads to several chronic diseases later in life (National Dietary Intake and Status Study in Bulgarian Schoolchildren, 2003; National behavioral risk factor survey among population aged 25-64, 2009). Sachdeva S. et al. (2013), Xia Wang et al. (2014) and Aune et al. (2017) report similar data for fruit and vegetable intake in different countries.

Paganini-Hill A. (2007) and Rosenheck R. (2008) establish a significantly positive relationship between fast food consumption and energy and fat intake witch lead to high risk of overweight, obesity in terms of BMI.
According to $\operatorname{WHO}(2015,2017)$ alcohol use causes death and disability at a relatively early stage in life. At the age of $20-39$, approximately $25 \%$ of the total number of deaths is due to alcohol. Smoking is the most important cause of premature death from a number of chronic non-communicable diseases. It's proved that $80-90 \%$ of chronic respiratory diseases; $80-85 \%$ of lung cancer; $30 \%$ of all malignancies and $25-43 \%$ of ischemic heart disease are directly related to smoking.

Low physical activity is one of the major risk factors for the occurrence of chronic diseases. Janssen I. and Leblanc AG. (2010) indicate that regular physical activity can help young people improve cardiorespiratory fitness, control weight, reduce symptoms of anxiety and depression, and reduce the risk of developing health conditions such as high blood pressure, heart disease, type 2 diabetes, obesity.

According to data of National behavioral risk factor survey among population aged 25-64 (2009) above $80 \%$ of the working-age population has insufficient physical activity during leisure and $75 \%$ of them do not exercise at all; $45 \%$ of Bulgarians spend 2 to 3,5 hours sitting daily. At half of the young people, in general, many hours of sitting are combined with low motor activity. Laura K, et al. (2016) present a data of $27.1 \%$ of high school students participate in at least 60 minutes per day of physical activity on all 7 days of the week. Long M. et al. (2013) and Loprinzi PD, et al. (2015) show similar low physical activity in youth both in frequency and intensity.

In the current study we will focus on some parts of healthy lifestyles which concern the prevention of non-communicable, socially significant diseases such as cardiovascular diseases, diabetes, obesity, etc.

The aim of this survey is to explore some aspects (nutritional habits, tobacco and alcohol use, phys- 
ical activity) related to the healthy lifestyle among young Bulgarians.

Material and Methods: The survey was conducted among high-school and university students from Sofia, Bulgaria. A WHO GSHS core questionnaire module (2013) was used as the basis for the survey. 218 people were interviewed, 138 women and 80 men, mean age $-24 \pm 6,3$ years. The participants were asked to provide information about their age, height and weight. BMI was calculated based on participant's data for height and weight.
The results were commented by gender and age (three age groups were identified - up to 19, 20-29 and 30 and above years old). The statistical analysis was performed using SPSS23.0. Descriptive statistics (mean $\pm \mathrm{SD}$, frequencies) were computed for all variables. Pearson Chi-Square test and ANOVA was used for comparative analyses.

\section{Results}

The basic morphological characteristics of the respondents (height, weight and BMI) are presented in table 1.

Table 1. Basic morphological characteristics of the sample (mean $\pm S D$ )

\begin{tabular}{|c|c|c|c|c|c|c|}
\hline & & $\mathrm{n}$ & $\begin{array}{l}\text { Age } \\
(y)\end{array}$ & $\begin{array}{l}\text { Height } \\
(\mathrm{cm})\end{array}$ & $\begin{array}{c}\text { Weight } \\
(\mathrm{kg})\end{array}$ & $\begin{array}{c}\text { BMI } \\
\left(\mathrm{kg} / \mathrm{m}^{2}\right)\end{array}$ \\
\hline \multirow{2}{*}{ טัँ } & Male & 80 & $23,9 \pm 5,9$ & $180,9 \pm 6,9$ & $79,5 \pm 11,5$ & $24,2 \pm 2,8$ \\
\hline & Female & 138 & $24,04 \pm 6,5$ & $166,4 \pm 6,5$ & $58,9 \pm 8,9$ & $21,3 \pm 2.9$ \\
\hline \multirow{3}{*}{ 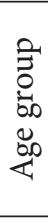 } & Up to $19(y)$ & 33 & $17,4 \pm 1,4$ & $170,1 \pm 8,9$ & $64,5 \pm 11,2$ & $22,2 \pm 3,4^{\star}$ \\
\hline & $20-29(y)$ & 165 & $23,4 \pm 2,3$ & $172,3 \pm 9,6$ & $65,8 \pm 13,9^{*}$ & $21,9 \pm 2,9^{*}$ \\
\hline & $30+(y)$ & 20 & $39,3 \pm 9,02$ & $169,7 \pm 11,1$ & $75,2 \pm 16,7^{\star}$ & $25,7 \pm 3,1^{\star}$ \\
\hline & Total & 218 & $23,97 \pm 6,3$ & $171,7 \pm 9,7$ & $66,5 \pm 14,03$ & $22,4 \pm 3,2$ \\
\hline
\end{tabular}

${ }^{*} p<0,01$

Based on the height and weight data of the respondents, a BMI was calculated. It should be noted that teenagers have a higher BMI, compared to people in their twenties, but it's still within normal range, while people over 30 have a pre-obese BMI.

\section{Nutritional habits}

Eating fruit and vegetables daily is a key element of rational feeding. Consuming those helps the body supplies the required vitamins, minerals and fibers, which support a healthy metabolism, and also prevents several diseases. The recommended consumption of these foods is about $2-5$ times a day.

The survey shows that $10 \%$ of the respondents do not eat fruit at all during the day, teenagers getting to $13 \% .40-50 \%$ of the respondents eat fruit and vegetables once per day and only a third of those do it twice a day (fig.1). Overall women eat fruit and vegetables more than men, but they all average at twice daily.

Consuming carbonated, nonalcoholic drinks and fast food has a bad influence on health, due to the increased carbohydrates and fat stored in the body, which can lead to obesity, diabetes and heart disease. The survey shows that $1 / 3$ of the respondents consume nonalcoholic drinks daily, and with age (especially over 30 ) that goes up 2-3 times daily.

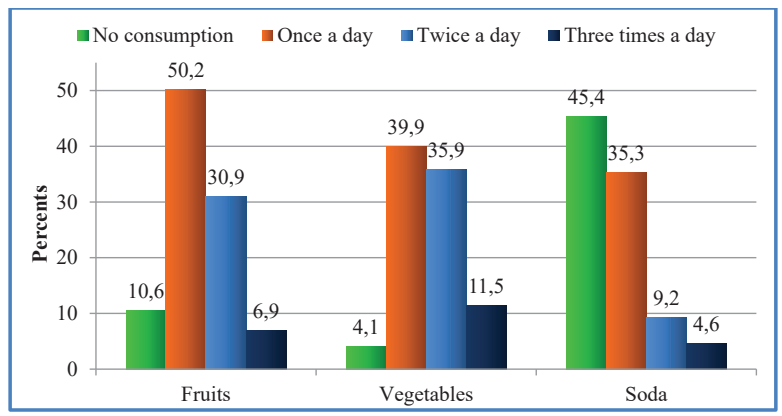

Figure 1. Fruits, vegetables and nonalcoholic beverage intake per day

In regards to fast food, every other respondent eats those foods, most commonly once a week, $5 \%$ of men in ages up to 30 eat fast food 5 times a week, which is 4 times more, compared to women of the same age (fig.2). 


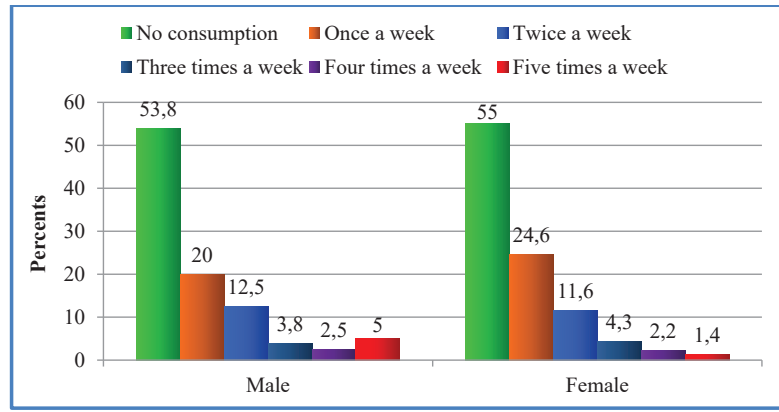

Figure 2. Fast food intake per week

\section{Alcohol and tobacco use}

Alcohol and tobacco use are a few of the proven risk factors in developing heart or lung disease. The earlier the age those bad habits develop, the bigger the risk of development of those diseases.

Early age of tobacco use is quite low. At age of 13, $13 \%$ of adolescents smoke, this percentage increase to $30 \%$ at the age of 15 (fig.3). Other than cigarettes, a third of the respondents smoke other tobacco products such as cigars or hookah, at least twice a month, each fifth of them is a teenager.

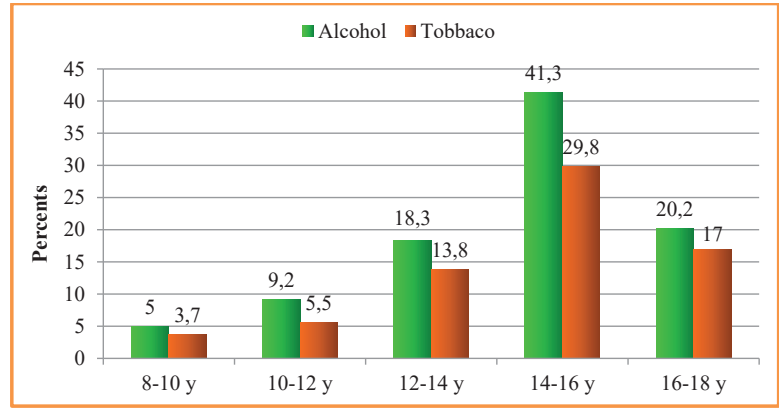

Figure 3. Age of first alcohol and tobacco use

Regardless of the ban on smoking in public areas, $45 \%$ of respondents are in a smoking habitat. The most vulnerable in that aspect are students; almost half of them are in contact with tobacco smoke, as passive smokers.

The data about alcohol consumption is even more alarming. $10 \%$ of male respondents have consumed alcohol for the first time between ages 8 to 10 , females doing it 5 times less (2\%). Regardless of gender, young adults (ages 20-29) drink alcohol at least twice monthly, with alcohol consumption increasing with age. Over a third of men have gotten drunk at least 10 times in their lives, making them skip class or work in $25 \%$ of the cases.

\section{Physical activity}

Physical activity has an important role preventing socially significant diseases. Teenage and youth have the highest physical activity and that is confirmed by the survey results. Most respondents are physically active 3 times a week (16.5\%) or daily (18.3\%). Males who do sports daily are 3 times more compared to Females. Unfortunately, 21\% of people of age up to 19 , have no weekly physical activity whatsoever, and women who don't engage sports are twice as much as men (fig.4).

Sitting for a considerable amount of time daily also contributes to low physical activity. A third of respondents are sitting down for at least 3-4 hours a day. $10 \%$ of female respondents remain seated for at least 8 hours a day, and with males it's about $4 \%$.

An active way of moving about contributes to physical activity. A quarter of respondents walk or bike daily, but just as much doesn't. Teenagers appear to move actively the most (39.4\%).

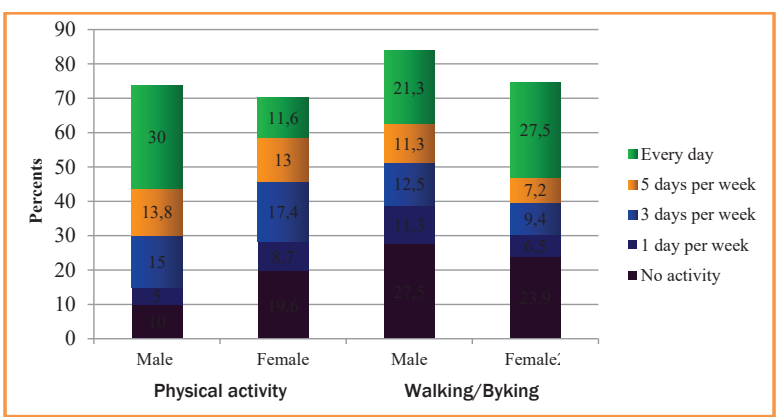

Figure 4. Physical activity (days per week)

\section{Conclusion}

Nutritional habits of young Bulgarians are not good enough. Fruits and vegetables intake is insufficient in contrast to the frequent use of fast food and nonalcoholic beverages. The use of tobacco and alcohol products begins too early in childhood. An increase in physical activity among young people is recommended. There is necessity of more adequate health promotion.

\section{References}

Aune D. et al. (2017) Fruit and vegetable intake and the risk of cardiovascular disease, total cancer and all-cause mortality - a systematic review and dose-response meta-analysis of prospective studies. International Journal of Epidemiology, 1029-1056

http://www.who.int/substance_abuse/publications/ global_alcohol_report/en/ (access 09/17/2017)

http://www.who.int/tobacco/global_report/2015/en/ 
(access 09/17/2017)

Janssen I, Leblanc AG. (2010) Systematic review of the health benefits of physical activity and fitness in schoolaged children and youth. IJBNPA, 7:40.

Laura K, et al. (2016) Youth Risk Behavior Surveillance United States, 2015. MMWR. 65(6):1-174.

Long M. et al. (2013) School-day and overall physical activity among youth. Am J Prev Med. Aug; 45(2):150-7. Loprinzi PD, et al. (2015) Association of concurrent healthy eating and regular physical activity with cardiovascular disease risk factors in US youth. A JHP, 30 (1): $2-8$.

National behavioral risk factor survey among population aged 25-64 (2009), Bulgarian Journal of Public health, vol. I, № 3(1)

National Dietary Intake and Status Study in Bulgarian Schoolchildren (2003). Edited by S. Petrova, NCPHP

Paganini-Hill A. (2007) Non-alcoholic beverage and caffeine consumption and mortality: the Leisure World Cohort Study. Prev Med. April; 44(4): 305-310.
Rosenheck R. (2008) Fast food consumption and increased caloric intake: a systematic review of a trajectory towards weight gain and obesity risk. Obesity reviews, 9: 535-547

Sachdeva S. et al. (2013) Increasing Fruit and Vegetable Consumption: Challenges and Opportunities. Indian J Community Med, Oct-Dec; 38(4): 192-197.

Xia Wang et al. (2014) Fruit and vegetable consumption and mortality from all causes, cardiovascular disease, and cancer: systematic review and dose-response meta-analysis of prospective cohort studies. BMJ. 349: g4490 doi:10.1136/bmj.g4490 (Published 29 July 2014) Corresponding address:

Evelina Miloshova MD, PhD

NSA "V. Levski",

Studentski grad 1700

Sofia, Bulgaria

Phone: 024014344

E-mail: emiloshova@yahoo.com 